\title{
THE INFLUENCE OF OCCUPATION ON THE PRODUCTION OF PHTHISIS.*
}

\author{
By JAMES NIVEN, M.A., M.B., \\ Medical Officer of Health of the City of Manchester.
}

THIs is a question of great complexity. We know from the statistics which have been prepared by the Superintendent of Statistics in the Registrar-General's office that phthisis falls much more heavily on certsin classes of work than on others. In some of these there are special factors at work, such as the production of an excessive amount of dust, or some influence specially enfeebling the system, as with workers in lead. In the case of publicans and their servants intemperance plays a prominent part in predisposing the system to attack. In many of the rougher classes of work there is uncertainty of work, with its frequent attendant intemperance. Here there is exposure to infection in the public-house, or in a certain proportion of cases in the common lodging-houses, in which a terrible mortality is exacted by this disease. Hence, in determining the influence of occupation on the production of phthisis, it is necessary to ascertain not only the statistical facts and the circumstances of employment corelated to them, but the social circumstances and habits of the operatives, and the part which these play in the production of the phthisis death-rate. It is also evident that the care or absence of care shown by the operatives in different employments as regards spitting in the workshops, and especially in the closets attached to them, will have an important influence, since a certain number of the workpeople, especially in the more unfavourable classes of work, will have phthisis, and the mischief resulting will depend largely on how they manage their expectorations.

The questions involved are of the utmost moment. Are the causes of our heavy industrial mortality removable? Do they explain the not infrequent obscure occurrences of phthisis in quarters in which it was not to be expected, and in which no trace of its origin can be ascertained?

In tracing the causes of phthisis in our large centres of industry, certain broad facts were first ascertained from the figures relating to occupations furnished by the Superintendent of Statistics in the Registrar-General's office. It was found that in nineteen out of fortyfour counties the female death-rate from phthisis exceeded the male, and that these were either agricultural or coal-mining counties. Further, it appeared that, while at early ages, both in town and country, the female phthisis death-rate exceeds the male, and at advanced ages the male phthisis death-rate exceeds the female, at intermediate ages, in nearly all large towns, the male death-rate begins to exceed the female at a much earlier age than in the country. There are thus factors at work in the towns, bearing heavily on males by comparison, which do not exist in the country. From the same statistical work it was possible to get an exhaustive view of the comparative mortality in different employments pursued by males between the ages of twenty-five and sixty-five. These could be classified into

* Abstract from Annual Report, 1902. 
three main groups : first, one containing a large number of certain labourers, etc., publicans and their servants, etc., known to suffer specially from intemperance; secondly, a purely industrial group; thirdly, a mixed group, comprising various classes of workpeople. It was very manifest from this classification that, apart altogether from specific injury inflicted by particular occupations, a special tendency to phthisis was manifest amongst the intemperate classes.

A special study of figures relating to alcoholism obtained from the same work appeared to show that workers in our large industrial centres suffer more from intemperance than workpeople living in the country. There is another set of conditions which affects the result, which may be classified as social, though its elements are difficult to determine. They comprise, however, insanitary houses, overcrowding, smaller wages, more precarious work, and so on.

We thus arrive at the classification of the factors operating to produce the high phthisis death-rate amongst males in our large centres as-social, alcoholism, effects of the occupation (direct and indirect).

Now, phthisis is an infectious disease, lasting usually some years, during which a very large amount of matter is expectorated, which contains frequently great numbers of tubercle bacilli. These bacilli possess great persistence of vitality, except in presence of direct sunlight, but do not readily produce the disease when inhaled, except in persons with weak lungs, or having constitutions in some way enfeebled. Nevertheless, the presence of the infective matter is a central fact, without which phthisis would not bo communicated. Now, where does spitting go on to the greatest extent? It is easy to ascertain that this is most abundantly practised in common lodging-houses, in many public-houses, in railway carriages, fand in the homes of careless consumptives. In the case of workshops, a most complete examination was made for a number of works, including two rubber factories, a cotton mill, a blacking manufactory, two large ironworks, a rag-sorting establishment, a large tailoring establishment, a chemical works, a small-ware establishment, a gasworks, a glass manufactory, a machinist's, and a cotton-spinning mill, in every detail which could be supposed to affect the health of the operatives. As regards expectoration, the marks of sputum on the floor were almost exclusively found in the male departments only. Hence males are much more exposed to infection than females in the workshops, on account of the deposit on the floor of a much larger amount of infection in proportion to the persons affected. That this is an important element in the propagation of phthisis is proved by these considerations. Dust taken from various portions of living rooms in which consumptives have expectorated on the floors is in a high proportion of instances capable of producing the disease.

The mortality from phthisis in common lodging-houses, where persons are often crowded together in living-rooms not well lighted, and in which cases of phthisis are often present, is very excessive. Publicans and their servants undergo a very high mortality from phthisis, and it is certain that infective matter plays an even more important part than alcoholism in producing phtbisis. It may therefore be assumed that in those works in which spitting is practised by the males the disease is certain to be propagated by tuberculous expectoration. Amongst the parts of workshops requiring attention especially are the attached closets, since expectoration was observed in these even when it was not present in the workshop, and the disease 
is here especially liable to be conveyed, the space being small, confined, and often dark. Thus, males are exposed to two specially disastrous influences, which affect females to a much smaller extent-viz., infection in the public-house, and infection in the workroom and attached closets. It is worth while inquiring whether the fountain of phthisis which is present in common lodging-houses and similar places cannot flow over into other classes of society.

In inquiring into the mortality from phthisis in one particular occupation, in which there did not seem much risk of infection through the employment, I found that some of the infected persons went to publichouses frequented by persons living in common lodging-houses. Phthisis is also comparatively prevalent amongst persons working at the Corporation gasworks and amongst the market porters, not a few of these also living in the common lodging-houses, while others use the same public-houses as persons living in common lodging-houses. No doubt these public-houses are a source of infection to many workmen not living in common lodging-houses, and who frequent also other public-houses. In this way the disease spreads outward from this intensely infected quarter, and probably passes from public-house to public-house.

When we come to inquire into the influence of common lodging. houses exerted indirectly through infection of articles passing through the hands of consumptive persons living in them, we are not able to ascertain that this is very great. Thus, from the return prepared by the Chief Constable in 1898 showing the occupations of the inhabitants of these houses, we find that, out of a total of 5,831, only 117 were tailors, and it is not possible positively to say of any other occupation yielding a considerable number of persons living in common lodging-houses that the articles produced in it would carry the disease. Out of these 117 tailors, perhaps 2.3 persons would die per annum from phthisis, an insignificant contribution to the occupational infection. Yet it can hardly be doubted that phthisis occurring in persons engaged in tailoring, or the manufacture of wholesale clothing, or in upholstering, or in house-decorating or painting, is liable to bring a sufficient amount of infective matter into the house to light up the disease in susceptible persons. At the same time, these influences must be small compared with the direct effect of contact with infective dust in the workshop and in the public-house.

How complicated is the relation of phthisis to occupation is seen from the fact that, when we investigate the incidence of notified cases of phthisis on different works of the same kind, some works stand out conspicuous in respect of the number of cases occurring in them and reported to us, and on investigating the individual cases, we find that there is not infrequently reason for connecting the occurrence of these cases with the social circumstances and habits of the workman. If, then, the social circumstances and habits of the workman affect the phthisis mortality in the calling which he pursues, does not the calling in return affect the social circumstances and habits of the workman? Undoubtedly such is the case.

Occupations such as those of market porters, messengers, and labourers, require that the persons pursuing them should live near the centre of the town, and that they should not pay very highly for their house room. They are thus often under conditions of overcrowding, and exposed to infection. Persons exposed to very high temperatures -strikers and moulders, cotton-spinners, glass-blowers, people in 
underground bakehouses, etc.-have, by virtue of the high temperature at which they work, a special tendency to consume large quantities of beer, and so to be injured in their constitutions as to be exposed specially to infection, and in this way the conditions of employment act indirectly on the health of the operatives. When, therefore, we come to consider the high mortality from phthisis which afflicts those pursuing special callings in which the statistics afford no proof of special addiction to alcohol, such as lead-workers, file-cutters, metalworkers generally, porters, tailors, etc., we must first make a considerable allowance for social conditions and habits, while recognising that these occupations present special injurious conditions which have to be dealt with. Some light is thrown upon the causes leading to a high occupational mortality by a study of the ages on which phthisis falls most heavily. If the chief incidence is on ages twenty-five to fortyfive, probably there is intemperance or some specially injurious factor in the occupation. If the incidence is high on an earlier age, the cause of the high mortality is, doubtless, occupational. If the chief incidence is on a later age, the cause is progressive, and may be the continued effects of the occupation or continued exposure to a high degree of infection.

The mortality from phthisis at different age-groups has been calculated for a number of occupations pursued in Manchester for the three years 1899, 1900, and 1901 .

Applying the above considerations, law clerks, coachmen, grooms (not domestic), and cabmen, persons employed in storage and porterage, messengers, porters, watchmen (not railway or Government), boot, shoe, slipper, patten and clog makers, inn and hotel keepers, publicans, etc., either suffer especially from intemperance and consequent special exposure to infection, or the occupation is specially injurious. There can be no doubt that the former is here the prevailing influence.

In the case of women, phthisis is most severe at ages fifteen to twenty-five amongst laundrywomen, and also amongst costermongers, hawkers, and street-sellers. Probably in the first occupation this must be taken to mean special exposure to infection, coupled with the effects of a severe occupation; amongst the latter it is probable that intemperance and hardship are conjoined. Charwomen also suffer heavily at early ages. They are exposed specially to infection, and probably suffer also from intemperance and domestic hardship. Charwomen, tailoresses, shirt-makers, and seamstresses suffer most heavily at ages twenty-five to forty-five. It is probable that this is due in the first class partly to infection, partly to habits, and that in the last two occupations the stress of the occupation tells heavily. In other occupations the stress falls on more advanced ages-commercial or business clerks, ironworkers, painters, decorators, glaziers, plumbers, glass manufacturers, cotton operatives (males), tailors, costermongers, hawkers, street-sellers, general labourers, cotton operatives (females).

In the case of ironworkers, there is no doubt the fact that they do not readily succumb to infection. With regard to the next two classes, their occupation exposes them mucb to house infection, and the effect increases with each year in which the calling is pursued. As regards glass manufacturers, the adverse influences are complex. These workers begin to suffer at an early age, and are known to be intemperate; but the work is throughout severe. In the case of cotton operatives, the system gradually gives way under the stress and strain of the work. It is the same with female cotton operatives; the atmo- 
sphere is unfavourable to health generally. The effect of occupation tells on tailors at a later age than on tailoresses. This is due, no doubt, to the persistence of infection in the male workrooms.

As regards the next two classes, the progressive mortality is due, no doubt, to the persistent presence of infection in the houses in which they live, which overrides the other influences. There can be little doubt that ironworkers, cotton operatives in Manchester, hawkers, and general labourers are, as classes, more intemperate than the average worker; but the other formidable influences at work keep piling up the death-rate. Thus, a cumulative death-rate, though it shows other powerful factors besides alcoholism to be at work, does not disprove the effects of intemperance, but merely obscures them. A notable feature in the Manchester table of occupational mortalities is the much higher mortality prevailing amongst men than amongst women following the same occupations at corresponding ages. This is, in all probability, due to the two factors on which stress has been already put-namely, spitting in the workrooms and closets used by the men, and intemperance amongst the males, in what relative proportions it is impossible to say.

The conclusions at which we arrive as the result of the analysis of our tables may be stated as follows:

The occupational mortality from phthisis is due in different occupations to very different groups of causes. There are, however, two outstanding factors which cause men to have much higher death-rates than women-viz., spitting in the workroom and drinking in publichouses. These enter into different occupations in very different degrees, and vary considerably even in the same occupations. They do, however, produce an effect on all, and their aggregate effect is much greater than that of particular occupational causes. Hence our first effort must be to diminish their general influence. For this reason notices with regard to spitting have been posted conspicuously in the various rooms of common lodging-houses. Other sets have been prepared for public-houses and for workshops. Another lesson which is practically enforced in common lodging-houses is the need for frequent and systematic cleansing. This is quite as necessary in public-houses and in workshops.

Sanitation ann Poverty.-The more one sees of public health work, the more one is impressed with the fact that the problem of sanitation is essentially the problem of poverty, and that the two are very largely interchangeable terms. It is the poorest who are the worst offenders against sanitation, and this is not to be wondered at, having regard to their conditions and surroundings. Moral precepts and sanitary principles, which appeal as mere platitudes to those nursed in the lap of plenty, necessarily lose their significance in the crowded hovels occupied by the poorest section of the community. If the problem of how to render the poor less poor can be aatisfactorily solved, then along with it will be solved half the sanitary problems of the day. Doubtless it must be to education that we must look chiefly for improvement, but it must be education of the right sort. It must be education which enlarges mind, strengthens judgment, and elevates character and aim. Whenever such a stage of education is reached sanitation is easy.Dr. Henry Kenwood: Annual Report. 